\title{
Central Nervous System Involvement in the Erythrophagocytic Disorders of Infancy: The Role of Cerebrospinal Fluid Neopterins in Their Differential Diagnosis and Clinical Management
}

\author{
D. W. HOWELLS, ' S. STROBEL, I. SMITH, R. J. LEVINSKY AND K. HYLAND² \\ Departments of Child Health [D.W.H., I.S., K.H.] and Immunology [S.S., R.J.L.], Institute of Child Health, 30 \\ Guilford Street, London WCIN IEH, United Kingdom
}

\begin{abstract}
In two children with familial erythrophagocytic lymphohistiocytosis accompanied by neurologic symptoms, total neopterin concentrations in cerebrospinal fluid were 200 times higher than in controls and 10 to 20 times higher than in five children with presumed neurologic disease due to primary viral infections (human immunodeficiency virus, herpes simplex, measles) of the CNS. In one child with familial erythrophagocytic lymphohistiocytosis, clinical remission was accompanied by a fall in neopterin concentrations to normal; in a second child, who died, total neopterin concentrations remained high. In two other children with a diagnosis of infection-associated hemophagocytic syndrome without any neurologic disturbance, neopterin concentrations were also elevated but only to 10 times the concentrations in controls. Total neopterin concentrations in cerebrospinal fluid provide a measure of the severity of macrophage infiltration and activation within the CNS, and are useful in assessing the need for intensive chemotherapy and monitoring the response to treatment. (Pediatr Res 28: 116-119, 1990)
\end{abstract}

Abbreviations

CSF, cerebrospinal fluid

FEL, familial erythrophagocytic lymphohistiocytosis

IAHS, infection-associated hemophagocytic syndrome

MTX, methotrexate

NH2, dihydroneopterin

VP16, etoposide

Systemic accumulation of histiocytes and lymphocytes undergoing active hemophagocytosis is found in FEL (1) and in IAHS (2, 3). Fever, hepatosplenomegaly, pancytopenia, and lymphohistiocytic infiltration of bone marrow, lymph nodes, liver, spleen, and meninges occur in both disorders $(1,2,4)$. However, FEL, which has an autosomal recessive mode of inheritance (5), is distinguished by an early presentation and more rapidly progressive tisue damage, particularly in the liver and CNS $(1,5,6)$; FEL is usually rapidly fatal unless intensive chemotherapy, including intrathecal MTX administration, is started early in the

Received August 23, 1989; accepted March 8, 1990.

Correspondence to: Dr. Stephan Strobel. Department of Immunology, Institute of Child Health, 30. Guilford Street, London WC IN, UK.

Supported in part by the Medical Research Council and Action Research for the Crippled Child (D.W.H., I.S., and K.H.).

'Present address: Murdoch Institute. Royal Children Hospital, Parkville, Victoria 3052. Australia.

${ }^{2}$ Present address: Baylor University Medical Centre, Dallas. Texas 75246. course of the disease $(7,8)$. IAHS, on the other hand, can occur at any age in association with infection and is often self-limiting (2). However, it can have a chronic relapsing course and may also benefit from chemotherapy.

Unless there is a family history of FEL, the differential diagnosis of the hemophagocytic disorders can be extremely difficult, particularly in young children $(1,4,9)$, and better methods are needed to distinguish the patients who require intensive chemotherapy.

Activated macrophages release neopterins in vitro and in vivo (Figure 1) $(10,11,12)$. Pterins generally move across cell membranes with difficulty; therefore, the concentrations of neopterins in CSF should provide a good measure of the extent of macrophage infiltration and activation within the CNS. Here we report on levels of CSF neopterins in four children with evidence of active hemophagocytosis, two of whom had neurologic involvement. The results are compared with those in five children with neurologic damage due to primary viral infections of the CNS (including two children with congenital human immunodeficiency virus infections and AIDS), which are known to stimulate neopterin production by macrophages $(10,12,13,14)$, and in 41 control children with various noninfective neurologic disorders.

\section{PATIENTS}

Children with hemophagocytic disorders. Presenting clinical features, diagnostic investigations, and neurologic manifestations are summarized in Tables 1 and 2; histological evidence of active hemophagocytosis was obtained in all four subjects. The diagnosis of FEL in patients 1 and 2 was based on the severe clinical diseases (including the neurologic involvement), the absence of infections and, in patient 1 , the positive family history. In patient 3 , the diagnosis of IAHS was made because of the late presentation, the absence of neurologic involvement, falling antibody titres to measles virus (1/256 to $1 / 32)$, and being Epstein-Barr virus and cytomegalovirus sero-positive at the time of presentation. In patient 4 , the diagnosis of IAHS was made because of the marked elevation of serum IgM at birth, which was suggestive of an intrauterine infection; however, repeated cultures and paired serum samples were consistently negative for the following organisms: cytomegalovirus, parvovirus, herpes, Epstein-Barr, respiratory viruses, enteroviruses, rubella, varicella zoster, toxoplasma, listeria, and treponema pallidum.

Children with primary viral infections of CNS. The diagnoses and neurologic features are summarized in Table 3. All five patients had severe neurologic disease, but none showed any evidence of hemphagocytosis in cytospins of CSF, bone marrow aspirates, or blood films.

Control children. These were 41 children aged 2-d to $16-\mathrm{y}$ who 
CELL

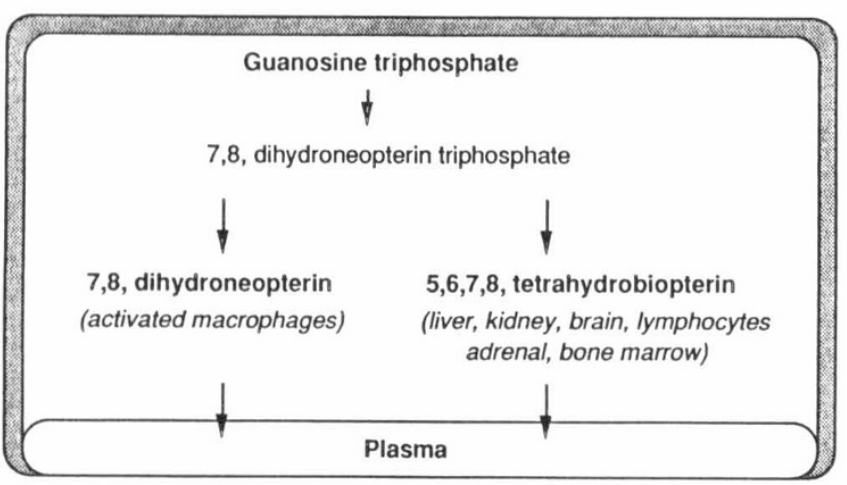

Fig. 1. Schematic diagram of the synthesis of 7,8 , dihydroneopterin in macrophages and 5,6,7,8,tetrahydrobiopterin in other cells.

underwent diagnostic lumbar puncture during the investigation of neurologic symptoms that included delayed development, epilepsy, and focal neurologic signs. Children with movement disorders were excluded because of the possible link with defective pterin metabolism (13). Children known to have inborn errors of phenylalanine or pterin metabolism, or with evidence of infection, were also excluded from the group.

\section{LABORATORY METHODS}

Previous studies demonstrated that reduced pterins in CSF are extremely labile and their loss is not accompanied by a corresponding rise in the concentration of the fully oxidized parent compound (14). To overcome this problem, lumbar CSF was collected into tubes containing $1 \mathrm{mg}$ of dithioerythritol and 1 $\mathrm{mg}$ of the chelating agent diethyleneetriaminepentaacetic acid, mixed, placed on solid carbon dioxide at the bedside, and stored at $-70^{\circ} \mathrm{C}(13)$.

Twenty five $\mu \mathrm{L}$ of CSF were analyzed by HPLC and pterins were separated at $25^{\circ} \mathrm{C}$ on a reverse-phase column $(25 \mathrm{~cm} \times 4.5$ $\mathrm{mm}$ inner diameter) (Jones Chromatography, Llanbradach, Wales) with a mobile phase containing sodium acetate $(6.8 \mathrm{~g} / \mathrm{L})$, citric acid $(1.05 \mathrm{~g} / \mathrm{L})$, EDTA $(20 \mathrm{mg} / \mathrm{L})$ and dithioerythritol $(24.7$ $\mathrm{mg} / \mathrm{L}), \mathrm{pH} 5.22$ eluted at $1.3 \mathrm{~mL} / \mathrm{min}$.

On this system, neopterin and dihydroneopterin coelute, allowing measurements of "total neopterin." The fully oxidized neopterin can be detected directly by fluorimetry [excitation 346 $\mathrm{nm}$, emission $444 \mathrm{~nm}$, Perkin-Elmer (Beaconsfield, Buckinghamshire, UK) LS-3 Fluorimeter]. A signal due to NH2 is only seen after electrochemical oxidation to neopterin using an ESA 5021 conditioning cell $(+1.0 \mathrm{~V})$ between the column and the fluorimeter (13). This method gives within-day and between-day coefficients of variation of 0.95 and $7.2 \%$, respectively (13).

In two of the patients with hemophagocytic disorders, NH2 and fully oxidized neopterin were measured individually using a modified assay system $(15,16)$.

\section{RESULTS}

In patients 1,2 , and $3, \mathrm{CSF}$ total neopterin concentrations were measured at diagnosis; in patient 4 , the first neopterin measurement was made at 7 wk of age, 6 wk after starting chemotherapy (Table 2). In patients 1 and 2, CSF neopterins were elevated more than 200 times above those of the control range although CSF cell counts were unremarkable. In patients 3 and 4, CSF neopterin concentrations were also raised, despite the absence of neurologic symptoms, but to values only 10 times higher than in the control group. In patients 1 and 4 , in whom $\mathrm{NH} 2$ and neopterin were measured separately, between 80 and $90 \%$ of the total neopterin was present as $\mathrm{NH} 2$ (Table 2).

The five children with viral infections of the CNS had CSF neopterin concentrations 10 to 20 times above those seen in
Table 1. Presenting clinical features and diagnostic investigations in four patients with hemophagocytic disorders*

\begin{tabular}{|c|c|c|c|c|}
\hline & \multicolumn{4}{|c|}{ Patient } \\
\hline & 1 & 2 & 3 & 4 \\
\hline Age at diagnosis (mo) & 3.5 & 4.3 & 19 & 0.14 \\
\hline Family history & + & - & - & - \\
\hline \multicolumn{5}{|l|}{ Clinical features } \\
\hline Fever (intermittent) & + & + & + & - \\
\hline Hepatosplenomegaly & + & + & + & + \\
\hline CNS involvement & + & + & - & - \\
\hline Evidence of infection & - & - & $\begin{array}{c}\text { Measles, } \dagger \\
\text { CMV, } \\
\text { EBV }\end{array}$ & $\begin{array}{r}\text { IgM } 219 \\
\mathrm{U} / \mathrm{mL} \neq\end{array}$ \\
\hline Hemophagocytosis & CSF & Liver & $\begin{array}{r}\text { Liver, } \\
\text { BM }\end{array}$ & Liver \\
\hline
\end{tabular}

Laboratory results

$\begin{array}{lcccc}\mathrm{Hb}(\mathrm{g} / \mathrm{dL}) & 6.3 & 8.0 & 5.7 & 18.0 \\ \text { Leukocytes }\left(\times 10^{9} / \mathrm{L}\right) & 8.6 & 4.5 & 2.3 & 4.2 \\ \text { Neutrophils }\left(\times 10^{9} / \mathrm{L}\right) & 2.5 & 0.49 & 0.0 & 2.4 \\ \begin{array}{l}\text { Platelets }\left(\times 10^{9} / \mathrm{L}\right) \\ \text { CSF cells }\left(\times 10^{6} / \mathrm{L}\right)\end{array} & 28 & 72 & 16 & 38 \\ & 2 & 24 & <1 & <1 \\ \begin{array}{l}\text { iagnosis } \\ \quad \text { (presumed) }\end{array} & \text { FEL } & \text { FEL } & \text { IAHS } & \text { IAHS }\end{array}$

* BM, bone marrow; CMV, cytomegalovirus; EBV, Epstein-Barr virus. $\uparrow$ Raised antibody titre at presentation, falling during follow-up (1/256 to $1 / 32$ ).

$\ddagger$ IgM age-related normal range at birth: $5-25 \mathrm{U} / \mathrm{mL}$.

controls and similar to those in patients 3 and 4 . The highest value was in a patient with subacute sclerosing pan-encephalitis after a measles infection.

All four patients with the hemophagocytic disorders showed severe clinical signs (Tables 1 and 2) and received chemotherapy with i.v. VP16 and prednisolone (7). In addition, patient 1 received intrathecal MTX over a period of $11 \mathrm{mo}$ according to a schedule similar to that proposed by Fischer et al. (7). Patient 4 received two doses of intrathecal MTX at $6 \mathrm{~d}$ and $7 \mathrm{wk}$ of age. Patients 2 and 3 did not receive any MTX.

Patient 1 responded to chemotherapy with a reduction in size of the liver and spleen, clearing of the histiocytic skin infiltration, and marked neurologic recovery; CSF neopterin concentrations fell to the normal range (Table 2). Patient 2 showed some clinical improvement initially, but 3 wk later developed increasing hepatosplenomegaly and liver failure, swinging pyrexia, and neurologic deterioration including refractory grand mal convulsions. Six wk after starting treatment, a CT scan showed bilateral subdural effusions. Chemotherapy was withdrawn and the child died $10 \mathrm{wk}$ after the onset of the illness. CSF neopterin concentrations $2 \mathrm{wk}$ before death were almost as high as at the initial presentation. Patient 3 responded to chemotherapy with complete recovery of hematologic parameters but died 6 wk later due to a Pseudomonas aeruginosa septicemia while still receiving VP16 through an indwelling central line. Patient 4 showed prompt reduction of his hepatosplenomegaly and marked improvement of his hematologic features; he gained wt normally and there were no abnormalities on EEG or CT scans. At the age of $2 \mathrm{mo}$, reduction in the dose of VP16 was followed within $1 \mathrm{wk}$ by enlargment of liver and spleen and a fall in the white cell and platelet counts. Reintroduction of VP16 lead to a resolution of the abnormal findings. At the age of $18 \mathrm{mo}$, he remained well but still required VP16 and prednisolone for control of hepatosplenomegaly and thrombocytopenia. 
Table 2. Neurologic features, CSF neopterins and white cell counts in four children with hemophagocytic disorders*

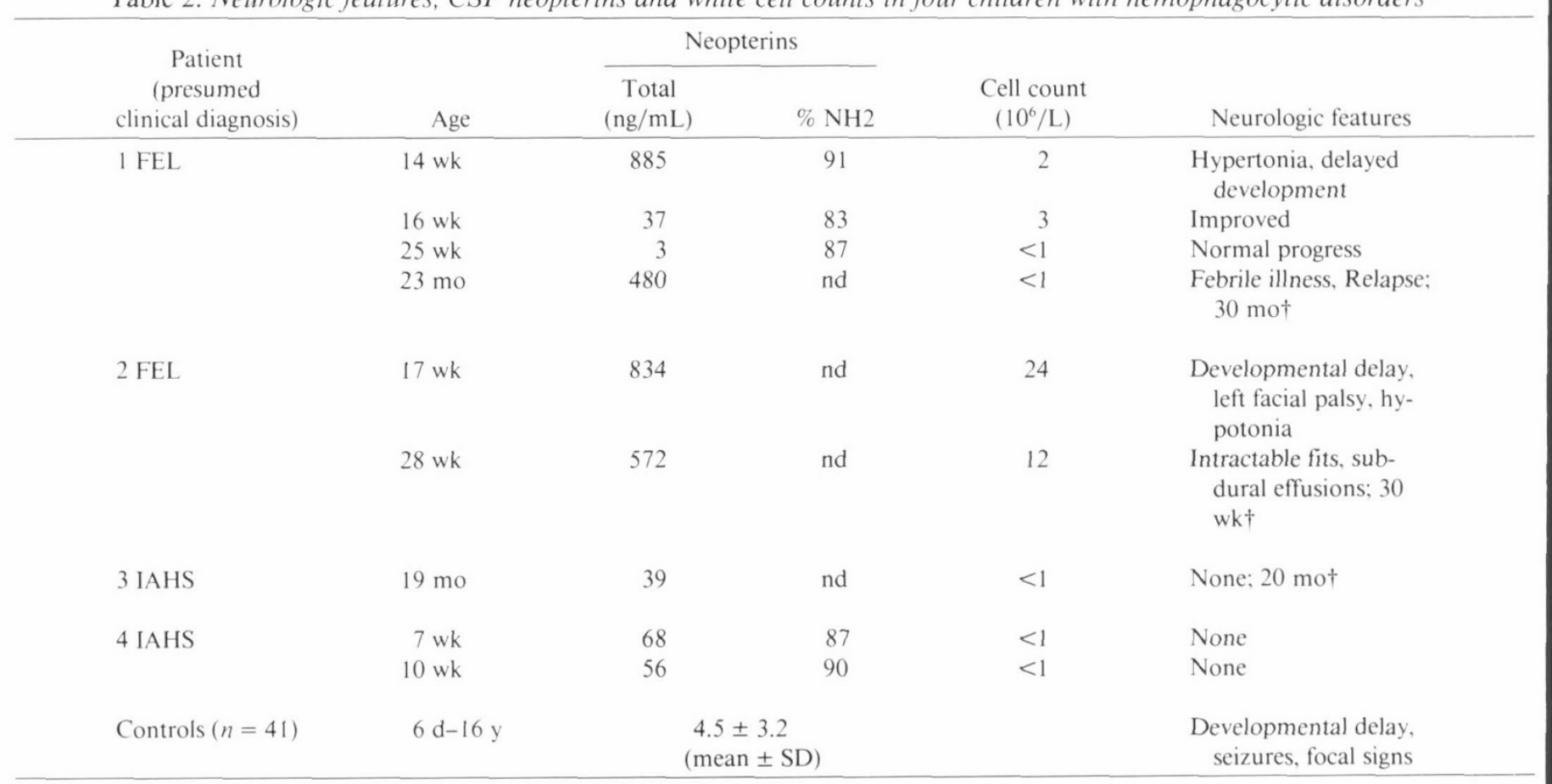

*nd, not done; NH2, 7,8, dihydroneopterin.

$\dagger$ Died.

Table 3. Neurologic features and CSF total neopterins in children with primary viral infections of brain*

\begin{tabular}{lcccc}
$\begin{array}{c}\text { Infective } \\
\text { organism }\end{array}$ & Age & $\begin{array}{c}\text { Total } \\
\text { neopterin } \\
(\mathrm{ng} / \mathrm{mL})\end{array}$ & $\begin{array}{c}\text { Cell count } \\
\left(10^{6} / \mathrm{L}\right)\end{array}$ & $\begin{array}{c}\text { Neurologic } \\
\text { features }\end{array}$ \\
\hline HIV & $33 \mathrm{mo}$ & 61 & $<1$ & $\begin{array}{c}\text { Fits, delayed } \\
\text { development }\end{array}$ \\
HIV & $33 \mathrm{mo}$ & 46 & $<1$ & $\begin{array}{c}\text { Delayed devel- } \\
\text { opment, } \\
\text { truncal hypo- } \\
\text { tonia }\end{array}$ \\
$\begin{array}{c}\text { Herpes sim- } \\
\text { plex }\end{array}$ & $27 \mathrm{mo}$ & 60 & 3 & $\begin{array}{c}\text { Fits, hypertonia } \\
\text { Herpes sim- } \\
\text { plex }\end{array}$ \\
$\begin{array}{c}\text { Measles } \\
\text { (SSPE) }\end{array}$ & $6 \mathrm{mo}$ & 51 & $\mathrm{nd}$ & $\begin{array}{c}\text { Hypotonia, ath- } \\
\text { etosis }\end{array}$ \\
\hline
\end{tabular}

* HIV, human immunodeficiency virus; nd, not done; SSPE, subacute sclerosing pan-encephalitis.

\section{DISCUSSION}

The four patients with hemophagocytic disorders described here illustrate the serious nature of this group of illnesses and the difficulties in distinguishing the familial from the infectionassociated disorder. Indeed, it has been suggested that FEL and IAHS are just different forms of the same condition $(4,9)$. The importance of the choice of treatment is also apparent and has been emphasized by others $(4,9)$. The patient with a diagnosis of FEL who received intensive chemotherapy, including intrathecal MTX, went into prolonged remission, but another who was not given MTX died of his disease. Although IAHS is generally thought to have a better prognosis than FEL, one of our patients died due to overwhelming infection secondary to chemotherapy and another remained dependent on chemotherapy over an 18mo period. The possibility that this child had FEL, rather than IAHS modified by early chemotherapy, cannot be totally excluded.

It is of interest that the two patients diagnosed as having FEL, both of whom had neurologic symptoms, also had CSF total neopterin concentrations a whole order of magnitude higher than in those two patients with a diagnosis of IAHS without neurologic involvement, or in the five patients with CNS damage due to viral infection. What is more, the patient with FEL who responded well to treatment showed a dramatic fall in CSF neopterin concentrations in parallel with the clinical remission. The findings suggest that measurement of CSF neopterin is a useful investigation in patients with hemophagocytic disorders when deciding whom to treat with intensive chemotherapy (including intrathecal MTX) and also for monitoring the response to therapy including the early detection of CNS relapse; CSF cell counts are often unhelpful in this respect (Table 2).

In the two patients in whom neopterin and 7,8 ,dihydroneopterin were measured individually, over $80 \%$ of the total was $\mathrm{NH} 2$. A similar preponderance of NH2 in urine (14) and in CSF (15) has been reported in subjects with infections. The data suggest that $\mathrm{NH} 2$ is the species released by macrophages and that the relatively small amount of oxidized neopterin that is present is likely to be derived from breakdown of NH2 $(12,14,15)$.

Very high CSF neopterin concentrations in the patients with erythrophagocytic disorders and especially in those with presumed FEL may reflect the uncontrolled activation of macrophages and invasion of the meninges and brain, which has been described in this condition at post mortem (6). In contrast, a possible virus titre-dependent (more modest) degree of macrophage activation seen in the patients with IAHS was also consistent with previous post mortem studies that have shown a small increase in phagocytic histiocytes in the leptomeninges (2). In the patients with viral infections of the CNS, the neopterin rise was consistent with the increased macrophage activity that is known to occur with most viral infections $(11,12)$. Furthermore, as seen in patient 1 , the measurement of CNS neopterins can also help in the early diagnosis of a CNS relapse without overt neurologic signs. The results also suggest that neopterin 
concentrations in the CSF may provide a measure of the severity of macrophage infiltration and activation within the CNS that cannot be provided by CSF cell counts alone. Only direct correlations between CSF neopterin levels and histochemical assessment of macrophage infiltration at post mortem will answer this important question.

The reason for the widespread and apparently uncontrolled macrophage activation in patients with hemophagocytic disorders remains unknown. Neopterin release by macrophages is thought to be dependent on stimulation by interferons produced by activated T cells $(10,11,12)$. However, reduced rather than elevated concentrations of $\gamma$-interferon have been reported in patients with FEL (1). An inherited abnormality of the $\gamma$-interferon receptor-signal transduction pathway leading to uncontrolled macrophage activation and feedback inhibition of interferon production, might explain the findings. In IAHS, where infection is thought to be the underlying stimulus for macrophage activity, a rise in interferons might be expected although, to our knowledge, there have been no prospective studies on interferon levels in the above conditions.

Further investigations of the interferon and neopterin responses in the hemophagocytic disorders might help elucidate the mechanisms of macrophage stimulation, aid in the differential diagnosis, and perhaps resolve the debate whether FEL and IAHS are different conditions or just two extremes of the same underlying disorder (4).

Acknowledgments. The authors thank the following consultants and their junior staff at the Hospital for Sick Children for allowing us to study their patients: Professor J. Chessells, Dr. J. Pritchard, Dr. V. Broadbent, Dr. J. Leonard, Dr. J. Wilson, and Dr. E. Brett.

\section{REFERENCES}

1. Janka GE 1983 Familial haemophagocytic lymphohistiocytosis. Eur J Pediatr $140: 221-230$
2. Risdall RJ, McKenna RW, Nesbit ME, Krivit W, Balfour HH, Simmons RL, Brunning RD 1979 Virus-associated haemophagocytic syndrome. A benign histiocyte proliferation distinct from malignant histiocytosis. Cancer 44:9931002

3. Weintraub M, Siegnan-Igra Y, Josiphov J, Rahmani R, Liron M 1979 Histiocytic haemophagocytosis in miliary tuberculosis. Arch Interm Med 44:20552056

4. The Writing Group of the Histiocyte Society 1987 Histiocytosis syndromes in children. Lancet 1:208-209

5. Genick A, Signer E, Muller HJ 1984 Genetic analysis of familial erythrophagocytic lymphohistiocytosis. Eur J Pediatr 142:248-252

6. Martin JJ, Cras P 1985 Familial erythrophagocytic lymphohistiocytosis. A neuropathological study. Acta Neuropathol (Berl) 66:140-144

7. Fischer A, Virelizier JL, Arenzana-Seisdedos F, Perez N, Nezelof C, Griscelli C 1985 Treatment of four patients with erythrophagocytic lymphohistiocytosis by a combination of epipodophyllotoxin, steroids, intrathecal methotrexate and cranial irradiation. Pediatrics 76:263-268

8. Henter J-I, Elinder G, Finkel Y. Soder O 1986 Successful induction with chemotherapy including teniposide in familial erythrophagocytic lymphohistiocytosis. Lancet 2:1402

9. Henter J-I, Elinder G, Soder O, Ost A 1987 Histiocytosis syndromes in children. Lancet 1:1091-1092

10. Huber C, Batchelor JR, Fuchs D, Hausen A, Lang A, Niederwieser D, Reibnegger G, Swetly P. Troppmair J, Wachter H 1984 Immune responseassociated production of neopterin. Release from macrophages primarily under control of interferon-gamma. J Exp Med 160:310-316

11. Lang A, Niederwieser D. Huber C. Swetly P. Fuchs D. Hausen A, Reibnegger G, Wachter H 1984 Treatment with recombinant interferon-alpha-2 induces increase of in vivo neopterin excretion. In: Pfleiderer W, Wachter H, Curtius $\mathrm{H}-\mathrm{C}$ (eds) Biochemical and Clinical Aspects of Pteridines. Walter de Gruyter. Berlin, pp 251-254

12. Editorial. Neopterins in clinical medicine 1988 Lancet 2:509-511

13. Howells DW, Smith I, Hyland K 1986 Estimation of tetrahydrobiopterin and other pterins in cerebrospinal fluid using reversed-phase high performance liquid chromatography with electrochemical and fluorescence detection. J Chromatogr 381:285-294

14. Hyland K, Howells DW 1988 Analysis and clinical significance of pterins. J Chromatogr Biomed Appl 429 (73):95-121

15. Howells DW, Smith I, Hyland K 1987 Dihydroneopterin and CNS infections Lancet 2:686-687

16. Hyland K 1985 Estimation of tetrahydro, dihydro and fully oxidised pterins by high performance liquid chromatography using sequential electrochemical and fluorimetric detection. J Chromatogr 343:35-41 